\title{
Time, Value, and Collective Immortality
}

\section{Michael Cholbi}

The Journal of Ethics

An International Philosophical Review

ISSN 1382-4554

Volume 19

Number 2

J Ethics (2015) 19:197-211

DOI 10.1007/s10892-015-9198-1

\section{THE JOURNAL OF ETHICS}

AN INTERNATIONAL PHILOSOPHICAL REVIEW

EDITOR-IN-CHIEF: J. ANGELO CORLETT

照 Springer 
Your article is protected by copyright and all rights are held exclusively by Springer Science +Business Media Dordrecht. This e-offprint is for personal use only and shall not be selfarchived in electronic repositories. If you wish to self-archive your article, please use the accepted manuscript version for posting on your own website. You may further deposit the accepted manuscript version in any repository, provided it is only made publicly available 12 months after official publication or later and provided acknowledgement is given to the original source of publication and a link is inserted to the published article on Springer's website. The link must be accompanied by the following text: "The final publication is available at link.springer.com". 


\title{
Time, Value, and Collective Immortality
}

\author{
Michael Cholbi ${ }^{1}$
}

Received: 20 May 2015/ Accepted: 23 May 2015/Published online: 3 June 2015

(C) Springer Science+Business Media Dordrecht 2015

\begin{abstract}
Samuel Scheffler has recently defended what he calls the 'afterlife conjecture', the claim that many of our evaluative attitudes and practices rest on the assumption that human beings will continue to exist after we die. Scheffler contends that our endorsement of this claim reveals that our evaluative orientation has four features: non-experientialism, non-consequentialism, 'conservatism,' and future orientation. Here I argue that the connection between the afterlife conjecture and these four features is not as tight as Scheffler seems to suppose. In fact, those with an evaluative orientation that rejects these four features have equally strong moral reasons to endorse the existence of the collective afterlife.
\end{abstract}

Keywords Immortality - Value $\cdot$ Time $\cdot$ Morality $\cdot$ Impersonal versus personal values

Samuel Scheffler argues that the intelligibility of our evaluative perspectives and practices rests on the largely unrecognized assumption that humanity will continue to exist after our individual lives end. More specifically, were we to lose confidence in the existence of the "collective afterlife," then "many of the things that now matter to us would come to matter to us less, in the sense that we would see less reason to engage with them, would become less emotionally invested in them, and would be less convinced of their value or worth." (Scheffler 2013: 51) Scheffler in turn takes the importance that we assign to the collective afterlife as manifestations of four central features of our evaluative outlooks. In particular, the importance of the collective afterlife indicates that our evaluative outlooks:

Michael Cholbi

mjcholbi@cpp.edu

1 California State Polytechnic University, Pomona, 3801 W. Temple Ave., Pomona, CA 91768, USA 
1. Are non-experientialist Assuming that we are not personally immortal and bodily death represents the cessation of our individual existences, we will not experience any events that occur after our deaths. The fact that we nevertheless care that humanity continues to exist after we die thus illustrates that "it is not only our experiences that we value or that matter to us." (Scheffler 2013: 20)

2. Are non-consequentialist The destruction of the human species would be bad in many ways, bringing to an end all human joy, love, and so on. But it would also mean the cessation of genocide, torture, and misery. But we do not, Scheffler proposes, naturally react to the prospect of imminent human extinction by trying to "do the sums, by trying to figure out whether on balance the prospect of the destruction of the earth was welcome or unwelcome." (Scheffler 2013: 21) This underscores how reasoned evaluative judgments rest on considerations besides which actions or events have the best overall consequences.

3. Are "conservative" There is, Scheffler asserts, "something approaching a conceptual connection between valuing something and wanting it to be preserved." (Scheffler 2013: 22) Hence, despite the fact that we will not be present when subsequent generations recognize or act upon our values, we nevertheless hope that those generations will exist in order to preserve our values (or perhaps other values that are least causal descendants of our values).

4. Include future-oriented personalization The role of the collective afterlife in sustaining our existing values reflects a desire for a "personalized" normative relationship with the future, according to Scheffler. Our mortality ensures that large portions of the future will not happen to us. Yet if humanity continues to exist after each of us dies, then it is at least possible for our human successors to share the very values over which we currently exercise custodianship. If so, then even though death brings our autobiographies to an end, our biographies continue inasmuch as we are not forgotten and our social identities persist beyond the time after our deaths. The collective afterlife assures us that if resurrected, we would not, Scheffler says, find the world inhospitable to our hopes and values. (Scheffler 2013: 29-34)

My aim in this paper is not to cast doubt on Scheffler's claim that each of us has reason to hope that humanity exists after we die. Nor is it to cast doubt on whether agents whose evaluative outlooks have the four features just enumerated would have reason to hope for the collective afterlife. Rather, my concern is to interrogate just how tight the connection is between the hope for the collective afterlife and these four features. In other words, would agents whose evaluative outlooks did not contain one or more of these features also have reason to hope that humanity exists after they die? I shall argue that they would - that agents whose evaluative outlooks are experientialist, consequentialist, non-conservative, and oriented impersonally toward the future would have at least as much reason to hope that humanity continues after they themselves cease to exist as would individuals whose evaluative outlooks encompass these four features. ${ }^{1}$ Hence these four features are not as

\footnotetext{
1 My critique of Scheffler is also germane to Lenman's position (2002) that only from a "generationcentered perspective" can human extinction be thought bad.
} 
essential to the rational hope for the collective afterlife as Scheffler believes. My critique thus has good news and bad news for Scheffler: His claim that we have reason to hope for the collective afterlife probably has wide appeal, but probably does not require the specific evaluative outlook Scheffler supposes it does. I conclude by illustrating how the contrast between the evaluative outlook Scheffler describes and the one I outline here rests on deep and largely unexplored philosophical disagreements about the relationship between time and value. Very roughly, for Scheffler, time's asymmetrical character, i.e., its movement through past, present, and future, in addition to time's scarcity within the lifetime of any one individual, renders intelligible our personal concerns and values. Whereas on the alternative evaluative outlook I describe here, time does not structure our individual evaluative outlooks and commitments. Time is simply a medium in which value can be realized.

I should say at the outset that Scheffler may not intend that the relationship between the hope for a collective afterlife and these four evaluative commitments to be especially strong. As he puts it, our hope for a collective afterlife "supports a nonexperientialist interpretation" of our values (Scheffler 2013: 20); "suggests" that our values have a nonconsequentialist dimension (Scheffler 2013: 21); "highlights" a conservative dimension to our valuing (Scheffler 2013: 22); etc (emphases added). ${ }^{2}$ So Scheffler does not state anything so strong as that the hope for a collective afterlife implies or requires these evaluative commitments. A more charitable reading, then, is that Scheffler holds that our hope for the collective afterlife is evidence for our evaluative outlooks having these four features, even if it does not logically imply their having these four features. If so, then my critique may be seen as undermining that evidence instead of demonstrating that our hope for the collective afterlife does not imply the four evaluative features Scheffler identities. In any event, the examination of the relationship between our apparent hope for the collective afterlife and the evaluative commitments that may or may not explain that hope is a fruitful exercise regardless of precisely how Scheffler understands that relationship.

\section{Non-experientialism}

Let us begin then with the claim that our hope for the collective afterlife illustrates that at least some of our values do not rest entirely on the qualities or contents of our experiences.

Scheffler acknowledges that entertaining scenarios in which the human species goes extinct causes many people distress. It is tempting, then, to infer that what is bad about human extinction is an experiential fact, namely, that existing human beings find that prospect upsetting, But that, Scheffler argues, gets matters the

\footnotetext{
2 See also Scheffler's reply to Seana Shiffrin (Scheffler 2013: 192-195), where he seems to backtrack on how fundamental conservatism, non-experientialism, and non-consequentialism are to our reactions to the prospect of human extinction.
} 
wrong way around: We either would not feel, or have any reason to feel, distress at the prospect of human extinction if that possibility did not matter to us already.

...what would matter to us, in the first instance, would not be our distressthough that might matter to us too-but rather the predicted postmortem event whose contemplation gave rise to that distress. If the postmortem event did not matter to us, there would be nothing for us to be distressed about in the first place. (Scheffler 2013: 20)

Scheffler takes the fact that we react to the prospect of human extinction with distress, or at least with something more than indifference, to show, in the spirit of Robert Nozick's "experience machine," that at least some of our values or cares do not derive from the qualities or contents of our experiences. In many cases, we care principally that some state of affairs comes about, not that we experience that state of affairs.

Exactly what we find distressing when contemplating human extinction is far from obvious. But a coherent story can be told wherein our distress is rationally explicable in terms of experiences alone being the bearers of value.

Suppose that Scheffler is correct that it is rational to react to the prospect of human extinction with distress. He is probably correct to say few of us would dismiss this distress on the basis that the destruction of humanity will not be something that happens to us. We will (most likely) not be present for the extinction of humanity, and so we must not be "indifferent to everything that happens after our deaths." (Scheffler 2013: 19) But the fact that the doomsday scenario will not befall us does not show that our distress at this scenario befalling our descendants is not ultimately grounded in attitudes toward experiences. It may, for example, matter to me that those of our descendants who must confront the species' extinction- the last generation, we may dub them-will themselves undergo many terrible experiences. They will, for example, see many of their projects and commitments fail to come to fruition, while all of their projects and commitments that will have come to fruition are nullified. Depending on precisely the doomsday scenario unfolds, the last generation may undergo repeated and profound grief as their loved ones die off. Likewise, their deaths and the deaths of others may be prolonged and painful. A being possessed with universal empathy is likely to experience the experiences of the last generation as distressing. When we contemplate other horrifying human fates (for example, life as a 'lucky' laborer in a Nazi death camp), we are horrified at what it would be like to suffer such a fate. At most then, Scheffler seems to have shown that our distress at the prospect of human extinction is powerful evidence against our normative solipsism, i.e., that we are capable of seeing the sad fates of others as worth lamenting, and where possible, worth preventing. Yes, "it is not only our experiences that we value or that matter to us." It is also the experiences of others. Experientialism, understood as the claim that only mental states are the bearers of value, is not refuted by our distress at contemplating the eventual destruction of the human species.

Scheffler may respond by claiming that these observations merely push back the question at hand. Suppose that our distress at human extinction is vicarious or at one remove, directed at the distress we imagine the last generation would experience. 
But why, he may ask, do the members of the last generation experience their distress then? May not Scheffler argue that my experientialist explanation of our distress runs aground, unable to explain the ultimate source of our distress?

Here we may turn to experientialist explanations of why death can be bad for individuals or merit fear. Many philosophers endorse the deprivation account of how death can be bad for an individual. (Nagel 1970) On this view, death is bad for a person not because the state of being dead is bad for us. Indeed, assuming that personal immortality is not in the offing, death is not a state of us but is instead, as Epicurus put it, nothing to us. Rather, death at a given moment in time is bad if, when, and to the extent that death at that time deprives a person of having a better life overall than she would have had by continuing to live to a further point in time. Death, on this account, is a comparative or counterfactual bad-not bad in its own right, but bad when it results in our lives not going as well as they would have. The deprivation account is of course compatible with any number of theories of value or well-being, including (most importantly for our purposes) an experientialist theory. In other words, death at a given time would be bad for an individual on the experientialist deprivation account if and only if the life that individual would have experienced by living to some future point in time would have been better overall than the life she experienced by dying at that time. If so, then our distress at the experiences of the last generation can be explained at least in part by our empathizing with their plights, namely, with the facts that their deaths will deprive them of valuable experiences that would have made their lives better for them overall.

Suppose, however, that the deprivation account of death's badness is incorrect. Scheffler believes that there is an additional reason for members of the last generation to fear death. He claims that a large part of our fear of death is "a special sort of panic induced by the prospect that the egocentric subject—-the subject of all one's thoughts and attitudes, including the very attitudes one is experiencing as one contemplates one's death-will cease to exist." (Scheffler 2013: 102) According to Scheffler, this is not a fear of the state of being dead. For even though we are certain that our being dead is a state that will eventuate, we may nevertheless fear the cessation of personhood death represents. But nor is this kind of fear of death a brute or involuntary physiological response. In Scheffler's eyes, the "unwanted cessation of one's existence" is rationally perceived as a threat to the existence of our persisting selves. (Scheffler 2013: 102-103) Presumably, this 'existential' fear will be especially acute or pervasive among members of the last generation, particularly if human extinction is the result of Scheffler's doomsday scenario, in which all of humanity is killed by a single catastrophic event. After all, the last generation is forced to confront, by virtue of their awareness of the species' imminent extinction, their own mortality, the cessation of their own existence, on an ongoing basis. We, on the other hand, have the luxury of not knowing the time or circumstances of our own demise. Our distress at the extinction of humanity may thus stem from an empathetic awareness that the last generation will be compelled to confront death in particularly harrowing ways.

Obviously, there are deep philosophical questions to be hashed out between experientialism and non-experientialism, particularly regarding the priority of 
experiences and their objects in explaining value. My point here is simply that our distress at the prospect that collective immortality is imperiled-that some future generation will be the last human generation-does not provide independence evidence against experientialism, as Scheffler seems to maintain. For we may coherently suggest that (a) the experiences of the last generation would be bad for them qua experiences, and (b) our distress is a rational experiential response to the last generation's likely experiences and is bad for us for that very reason.

\section{Non-consequentialism}

Scheffler also claims that our distress at the prospect of humanity disappearing reveals our non-consequentialist evaluative commitments. He predicts that we would not react to this prospect by summing up the value of the good and bad outcomes associated with humanity's disappearance. Our distress thus seems to transcend consequentialist considerations.

I suspect Scheffler is probably correct that our immediate theoretically naive response to the prospect of human extinction is that it is a catastrophic tragedy. However, it is not obvious that this response should be taken as the last word. In one respect, that immediate reaction may be consequentialist but egocentrically so: We intuit, however dimly, that human extinction would be bad for us as individuals. Indeed, if my earlier remarks about experientialism are correct, our initial response may reflect a desirable sympathy with those future individuals who will constitute the last generation. So I do not believe that our initial response is necessarily a nonconsequentialist one.

Beyond this, it is worth noting that Death and the Afterlife does not primarily treat human extinction as a practical problem. Scheffler is centrally interested in establishing claims about our attitudes toward human extinction and what these attitudes in turn tell us about our evaluative practices. And while there are nods in the direction of the practical thesis that (given our apparent evaluative investment in the collective afterlife) we ought to act so as to ensure the future survival of humanity, Scheffler generally does not address human extinction as a problem about which we should try to do anything. However, were we to think of human extinction as a practical problem, impersonally consequentialist considerations should certainly play a central role in our deliberations about that problem.

Suppose that Scheffler's afterlife conjecture is correct: Our values and well-being depend crucially on the existence of subsequent human generations capable of valuing in the ways that we do. What importance should this dependence have in our deliberations about human procreation and population? One of the strange conceits of the branch of philosophy known as "population ethics" is that choices relevant to future populations are presented as if they were made from the perspective of a social engineer or policymaker. While polities engage in "population ethics" choices inasmuch as they have policies that provide incentives for or against procreation, the number and constitution of future human populations are largely the result of many individual choices and actions. But suppose we indulge that conceit for a moment and imagine that we, acting as if a single person, 
could determine the future human population. Suppose further that we learn that the human population, for whatever reason, is in steady and rapid decline. Again, Scheffler may be correct that our initial individual response to this news would have a non-consequentialist feel: utter disbelief, shock, distress, without reference to the possible benefits of human extinction. But once we moved to the sustaining of the human species as a practical challenge, consequentialist considerations would be paramount. If Scheffler is correct, then the threat human extinction poses to our value should be abated. But few would think that we should sustain our values by ensuring the existence of future generations no matter how those generations might live. Suppose that the rapid deterioration in the human population is due to accelerating environmental degradation, and while we could act now to ensure the existence of future generations, those generations would have lives barely worth living. No reasonable person would deny that the poor level of welfare of these future individuals ought to play some role in our deciding whether or not to bring them into existence. This would in turn compel us to ask how important the collective afterlife is to our own values and well-being. In other words, could the misery of these future humans be sufficient to persuade us not to try to abate the decline in human populations, even when juxtaposed with our being assured that these future generations will enable our own values to endure?

In entertaining such questions, our reasoning would have the hallmarks of consequentialist thinking: weighing different outcomes, taking into full account both facts that would contribute to different outcomes being better and facts that would contribute to different outcomes being worse, perhaps identifying the state of affairs that we might produce which has the best outcome overall, and so on. I readily concede that the determinations we might make in such circumstances could be guided in a non-consequentialist way. Inspired by LeGuin (1973) we might, for example, decide that it would be wrong to bring individuals into existence so as to sustain our own evaluative practices and outlooks, especially if those individuals will have barely livable lives. We might see bringing those individuals into existence as an egregious instance of treating them merely as means. But if we arrived at such non-consequentialist conclusions, we are likely to be led to them by reasoning about these population choices, not because that reasoning presupposes a non-consequentialist moral framework.

Just as I did not attempt to show that our distress at the prospect of human extinction decisively favors an experientialist over a non-experientialist account of value, I do not attempt to show that how we react and respond to the prospect of human extinction decisively favors a consequentialist over a non-consequentialist account of moral reasoning. However, when we approach human extinction not purely as a matter of the attitudes that prospect elicits but as a matter of choices about whether to prevent human extinction, consequentialist considerations come to the fore in an especially forceful way. Again, our reactions to the prospect of human extinction do not seem to provide independent evidence for a non-consequentialist interpretation of our evaluative habits and attitudes. 


\section{Conservatism}

Scheffler claims that death poses a problem for our "conservatism" about value. "We want to act in ways that help to preserve and sustain the things that we value, but death marks the end of our ability to do this." (Scheffler 2013: 32) Enter the collective afterlife. For Scheffler, the collective afterlife holds out the hope that the story of a person's life does not end when the person's life ends. If others capable of sharing values like ours will exist after we die, then even though dying is the final act of our lives, the future nevertheless turns out not to be a world hostile to or alienated from our values, "more like a party one had to leave early and less like a gathering of strangers." (Scheffler 2013: 30) We therefore hope to be able to bequeath our values (or at least our valuing) to generations that will exist after us.

Scheffler takes the relationship between this conservatism and value to be very tight indeed, "something approaching a conceptual connection." Before considering whether he is correct about that, we should consider how this conceptual connection is to be understood. It is unlikely that Scheffler is proposing this as an identity claim regarding value, i.e., that the property of something being valuable just is the property of being such that we want to act to preserve and sustain it. In the spirit of Moore's question argument, it does not seem incoherent to ask of some thing which we wish to preserve or sustain whether it is also valuable. The claim does not therefore seem to be true as a matter of semantics. Nor does it seem likely that Scheffler offers this claim as one of necessary coextension, i.e., that any and all valuable things are also such that we want to act to preserve and sustain them, and vice versa. Such an interpretation would be vulnerable to putative counterexamples. Being a child may be a valuable stage of life, but it seems misguided to want to preserve one's childhood-to remain a child-in perpetuity.

Most likely, Scheffler's claim, if true, is true as a matter of conceptual entailment. One possibility for this entailment is

(V) To value $\mathrm{x}$ is to want to act in ways that help to preserve and sustain $\mathrm{x}$

(V) implies that those who are conceptually fluent with the notion of 'value' could not fail to recognize that valuing something involves wishing to preserve or sustain it. For on standard ways of characterizing conceptual truths, a statement expresses a conceptual truth if and only if anyone who grasps the thought expressed by the statement recognizes its truth. In the case of conceptual truths, assent follows more or less immediately upon understanding. (Williamson 2006) Can it plausibly be said of (V) that assent follows upon understanding, that a grasp of its content results in a grasp of its truth? To my eyes, it is certainly conceivable that a grasp of this claim's content need not result in an individual's grasp of its truth. Suppose that (V) is true, but someone sincerely disputes (V). Of what can such a person be justly accused? The most reasonable accusation is probably not conceptual incompetence. Scheffler may maintain that the truth of $(\mathrm{V})$ will really dawn on anyone who fully grasps the claim. After all, he intends (V) to be a truth that we can genuinely discover thanks to reflection on how we would react to the prospect of human extinction. Even those who have not discovered the truth of $(\mathrm{V})$ will discover it to be true with adequate 
reflection, and perhaps understanding (V) is the only route to knowing it to be true. Nevertheless, if (V) represents the conceptual connection Scheffler has in mind, then that connection can be sensibly questioned.

But Scheffler is on better ground, I would suggest, if the conceptual connection is the opposite of that found in $(\mathrm{V})$ :

(W) To want to act in ways that help to preserve and sustain $\mathrm{X}$ is to value $\mathrm{X}$

(W) is a claim wherein it seems more reasonable to challenge the conceptual competence of someone who questions it. If we encountered someone who wanted to preserve or sustain $\mathrm{x}$ but did not also believe in x's value (either for its own sake or for its relation to other values), it would be natural to wonder what the source of their desire to help preserve or sustain $\mathrm{x}$ is if not in $\mathrm{x}$ 's being valuable (in her own estimation, at least). So whereas "I value X, but I don't want to preserve or sustain $X$ " does not seem to betray any conceptual misunderstanding or lack of understanding regarding value, "I want to preserve or sustain X but I don't value $\mathrm{X}$ " betrays a conceptual misunderstanding or lack of understanding regarding value.

(W) thus appears to be the better interpretation of the conceptual basis of the evaluative conservatism Scheffler identifies. Unfortunately though for Scheffler, the reasons that render (W) plausible need not lend support to conservatism as such. In keeping with the themes of the previous two sections, suppose that experientialism and consequentialism are true-that all and only mental or experiential states are bearers of value, and that the moral justifiability of our actions depends solely on the net values of the states of affairs those actions bring about. From that point of view, (W) might seem unlikely. After all, (W) seems to rest on a cross-temporal conception of value. For Scheffler, the desire to preserve and sustain $\mathrm{X}$ into the future (and in turn the desire for a collective afterlife) reflect the rootedness of our values in our personal and collective pasts. This is evident in how he relates conservatism about value to "traditions". Traditions are collaborative practices that aim to preserve values beyond the lifespan of any single generation or individual. When we propagate traditions, we seek to ensure the value "over time" of what we value. (Scheffler 2013: 33) From Scheffler's perspective, traditions are not good only because of what they are traditions of. Part of what makes traditions valuable is instead their cross-temporal dimension. We have reason to maintain those worthwhile traditions because traditions forge evaluative relationships among past, present, and future. The reasons to sustain or preserve our traditions derive in part from how they extend our evaluative outlooks into the future.

Those subscribing to experientialism and consequentialism will not be hostile to traditions as such. But they will see traditions merely as vehicle for the realization of what is timelessly valuable. Such traditions reflect discoveries about what is valuable or worthwhile, and their value derives wholly from what they are traditions of. The location of a tradition in time (when it begins or ends, etc.) is not any part of their value. A tradition of doing $\mathrm{x}$ is valuable because doing $\mathrm{x}$ is valuable, irrespective of our temporal relationship to the tradition.

Yet from this consequentialist and experientialist point of view, to want to preserve and sustain some valuable $\mathrm{x}$ can be perfectly intelligible inasmuch as 
preserving or sustaining $\mathrm{x}$ amounts to no more than promoting $\mathrm{x}$. Advocates of this point of view may therefore affirm that we ought to hope for or work actively to bring about $\mathrm{x}$-type occurrences, both for ourselves and for future generations. But our reasons for this need not be Scheffler's cross-temporal reasons. They are instead familiar teleological or forward-looking reasons - that a better world results when $\mathrm{x}$ is 'preserved' or 'sustained'.

(W) can therefore be defended on terms very different from Scheffler's conservatism. The conceptual link between value and 'preserving' or 'sustaining' values need not be explained by appeal to Scheffler's cross-temporal understanding of value. We may instead see the link as reflecting the insight that preserving or sustaining values makes for more value and for more valuable experiences overall. Again, our reactions to the prospects of human extinction, and our corresponding hope for a collective afterlife, can rest on an evaluative foundation different from Scheffler's preferred foundation.

\section{Personalization}

Lastly, Scheffler argues that our distress at the prospect of human extinction, and our hope for a collective afterlife, indicates our yearning for a "personalized" relation with the future. If there exist generations who succeed us and share our values, or something like those values, then the future does not present itself to us as a hostile or alien evaluative world. Our distress at the prospect of extinction thus reflects our being denied the possibility of a personalized relationship with the future.

Could our distress at the prospect of human extinction, and our hope for a collective afterlife, make sense absent a desire for a "personalized" relationship to the future? An affirmative answer becomes plausible once we take stock of the sort of conception of selves Scheffler seems to presuppose in his arguments for his afterlife conjecture.

For Scheffler, even though dying is the final act of our lives, if there are successor human generations, then our values may find a home in future generations. We therefore hope to be able to pass the torch of our values (or at least of our valuing) to generations that will exist after us. These sentiments regarding the relationship between time and value will resonate with those who have what Galen Strawson has called the Narrative outlook on selfhood. (Strawson 2004, 2007) This outlook both a metaphysical component and an autobiographical component. First, those with the Narrative outlook views their selves as 'diachronic,' as entities that experience themselves as existing in the past and in the future. For a Narrativist, various events in the past are understood as having happened to the very same present self who recalls them. Conversely, Narrativists anticipate various future events as events that will happen to the present self who anticipates them. Second, Narrativists impose narrative 'form' on these events, with the result that they grasp or articulate their lives as stories (and to the degree that they cannot grasp their lives as stories, strive to fashion more narratively coherent lives for themselves). Strawson states little to elaborate what it is for a life of a person or a self to constitute a story or narrative. 
We may adduce, however, that at a minimum, to have a narrative conception of oneself is to assign variable 'narrative' significance to the events that happen to oneself. A narrative is not just one damned (or blessed) thing after another. Instead, a narratively organized life is structured by recognizably narrative elements. Narratives have beginning, middles, and ends. Furthermore, these stages are characterized by development, the onset of tensions or life challenges, climaxes, the resolution (whether apparent or real) of tensions or challenges, etc. Each of these stages will have their respective characters as well. At its most expansive, a narratively lived self experiences her life as a single narrative, though of course that single narrative will also contain many 'substories' or subplots with their own respective narrative elements and structures.

In attempting to demonstrate the centrality of the collective afterlife to our evaluative practices and commitments, Scheffler endorses both the metaphysical and autobiographical components of the Narrativist outlook on selfhood. He clearly sees human valuers as beings who conceptualize their personhood as extending from the past, through the present, and into the future: In valuing, we "express our own understanding of ourselves as temporally extended creatures with commitments that endure through the flux of daily experience." (Scheffler 2013: 61, emphasis added) That we seek to uphold traditions, "collaborative, multigenerational enterprises devised by human beings precisely to satisfy the deep human impulse to preserve what is valued" (Scheffler 2013: 33) is further evidence for attributing the Narrativist outlook to human beings. Schefflerian selves are therefore diachronic selves. Though Scheffler does not explicltly use narrative language, he evidently endorses the autobiographical component of the Narrativist outlook as well:

... we understand a human life as having stages, beginning with birth and ending with death, and that we understand each of these stages as having its characteristic tasks, challenges, and potential rewards. ...the fact that life is understood as having stages, is, I take it, a universal response to the realities of our organic existence and our physical birth, maturation, deterioration, and death. (Scheffler 2013: 96) ${ }^{3}$

Narrativist thinking further illuminates Scheffler's reasons for believing in the importance of the collective afterlife. Scheffler's worry is that without the existence of subsequent generations of human valuers, our own lives as valuers-our evaluative biographies, if you will-will lack satisfying conclusions or denouements. The collective afterlife ensures that the fate of our evaluative biographies do not hang in the balance. For we can at least hope our values survive our own nonexistence. Thus, Scheffler's argument for the desirability of the collective afterlife is congruent with the Narrativist's "concern for one's past and future self, in so far as the self has an ongoing engagement in the realisation of the non-immediate achievements, goals, and possibilities that form and contribute to the narrative construct.” (Behrendt 2007: 144)

\footnotetext{
3 See also Scheffler (2013): 100, where he speaks of these stages as being "essential to our idea of a life that is temporally bounded."
} 
I think, then, that we can safely attribute the Narrativist outlook to Scheffler. Moreover, Scheffler unwittingly helps to answer a challenge that death presents to the Narrativist outlook. For Narrativists, personal immortality would not obviously be welcome. After all, it might be thought that a coherent and unified narrative cannot be fashioned out of an infinitely long existence. We seem, therefore, to need death to secure life's ending, an ending without which we are necessarily precluded from adopting a narrative-like perspective on our existences. (MacIntyre 1984: 211-212) As Scheffler seems to affirm, "an eternal life would, in a sense, be no life at all." (Scheffler 2013: 95) Kathy Behrendt observes, however, that death does not bring a person's life to narrative fruition in the way that, say, a literary narrative is brought to fruition. (Behrendt 2007: 149) We can often project or imagine narrative arcs for a novel left unfinished, such as Twain's Mysterious Stranger, largely because such works can be analyzed in terms of completed literary narratives with which we are otherwise familiar. But the narrative perspective of a life is not that of the external observer trying to make sense of another's story from the outside. Rather, the relevant narrative perspective on a person's life is that of the person whose life it is. For Narrativists, narrative is at the heart of self-understanding or self-definition (whatever the role of narrative may be in enabling our understanding of others). Except in some cases of suicide, death typically brings life to a close without the 'author' of that life being afforded the opportunity to conclude the narrative. Death thus renders our self-narratives "necessarily incomplete," and in so doing, casts doubt on the Narrativist aspiration to live a "closed" and "completed" life by the person whose life it is. (Behrendt 2007: 151)

Scheffler's arguments for the desirability, nay, the normative indispensability, of the collective afterlife do not address this problem directly. Yet he seems implicitly to recognize the problem described by Behrendt. Because our lives are fragile and finite, our life stories, and especially the values encoded within those stories, are fragile too. Scheffler does not meet Behrendt's problem on its own terms, showing how our fragile and finite lives can nevertheless achieve narrative unity from within our own individual perspectives. Indeed, he concedes they cannot achieve such a unity. Scheffler instead reconfigures the problem so that responsibility for our selfnarratives falls to subsequent generations. Our personal narratives, truncated by death, can achieve a sort of closure or conclusion if there exist subsequent generations who preserve our values. We are, according to Scheffler, ultimately dependent for the Narrative coherence of our lives on those who (we hope) will come after us. Having staked our claim to our own values, we nevertheless take the risk of leaving their fate, and the fate of our own self-narratives, to others. Our lives are redeemed not through our own works, but through the grace of others.

Strawson contrasts the Narrativist outlook with his own self-awareness, which he dubs "episodic". An Episodic "does not figure oneself, considered as a self, as something that was there in the (further) past and will be there in the (further) future." (Strawson 2004: 430). The self of the episodic is punctate, with "little or no sense that one was there in the (further) past and will be there in the future, although one is perfectly well aware that one has long-term continuity considered as a whole human being." Lacking a sense of a persisting self, "Episodics are likely to have no particular tendency to see their life in Narrative terms." (Strawson 2004: 430) 
Strawson does not seem to be denying diachronic personal identity outright: We have, he writes, "long-term continuity as a whole human being." But that continuity does not rest on anything like first-personal psychological continuity.

So far as I am aware, no systematic studies have been done regarding the prevalence of the Narrativist and Episodic outlooks within human populations. Yet supposing that the Episodic self-understanding is coherent and possible, then such individuals neither have nor desire a personalized relationship with the future. The issue at hand is whether Episodics might have reason to lament human extinction anyway. They clear cannot have the reasons Narrativists have for such lament, namely, that their life narratives will be prematurely truncated if there are no subsequent generations to share their values. Episodics presumably have no interest in having coherent life narratives.

Yet Episodics may recognize reasons for lamenting human extinction that are arguably as morally upright as those recognized by Narrativists. The Narrativist hope for a collective afterlife is strangely egoistic. Her own evaluative narrative will not be complete unless subsequent generations exist to complete it. For Episodics, the role of the collective afterlife is not to ensure that their self-conception is vindicated by the passage of time, for they lack any such cross-temporal selfconception. Episodics see value in the collective afterlife simply in the fact that to the extent that the human species existing for a longer duration rather than a shorter one brings about greater overall value, then the collective afterlife represents a closer approximation to a moral ideal. Of course, as we saw in Sect. 2, whether this is so is a contingent fact, and so for Episodics, there are not reasons as such to hope for the collective afterlife. Yet Episodics can coherently hope for the continued existence of the human species on the grounds that its continued existence results in a better state of the world overall. Our hopes, after all, need not all flow from personal reasons.

\section{Conclusion}

I have sought to show that at the very least, the apparent reasonableness of hoping for the collective afterlife does not have the evaluative implications Scheffler posits. Beings who embrace experientialism and consequentialism but reject conservatism and the necessity of a personalized relationship with the future have reasons, at least as strong as the beings envisioned by Scheffler, for wanting the human species to survive (and flourish) well beyond their deaths. The nature of these reasons differs from Scheffler's; they are impersonal and consequentialist.

Most crucially, time functions very differently in structuring the valuing practices of such beings. On Scheffler's picture, we are beings for whom the fact that time passes asymmetrically_-from past to present to future - is both metaphysically and ethically fundamental. We experience ourselves not merely as moving through time but as narratively shaping time's passage to our own ends and ambitions. Scheffler does not put it this way, but the temporal boundedness of human life seems to function as a necessary condition for value to be personal. Were we immortal, then much of the conceptual repertoire we use in practical deliberation, including loss, 
illness, injury, risk, and so on, would have no application, according to Scheffler (Scheffler 2013: 96-97). Valuing is an attempt to impose order on the contingencies that unfold over time, to make time

answerable to us. To value something is to resist the transitoriness of time; it is to insist that the passage of time lacks normative authority. Things may come and things may go, but we decide what matters. (Scheffler 2013: 61)

In effect, we need mortality and the temporal scarcity in order to render our "assignments of value" coherent (Scheffler 2013: 99). Yet death, on this picture, is significant not only because it makes time personally scarce. It also interrupts our efforts to impose a normative order on time. The existence of future human generations (Scheffler hopes) can rescue us from this evaluative disintegration.

Here I have outlined an alternative normative framework-experientialist, consequentialist, non-conservative, personally unconcerned with whether one's values survive into the future-that provides a different framework for justifying Scheffler's afterlife conjecture. This framework does not assign time the same relationship to value as Scheffler does. For Scheffler, time is a medium we seek to shape and differentiate, both individually and collectively, in an effort to harness time to our own purposes. The alternative framework I have suggested here sees time as a brute metaphysical condition or limit, but one lacking the ethical significance Scheffler assigns it. Under this framework, time is more akin to a shapeless or homogeneous space each of whose parts are of equal ethical significance, each moment identical to any other insofar as it represents an opportunity to realize what is valuable. To the extent that realizing more value requires more people, and more people requires more time during which people may exist, the collective afterlife is valuable simply because it may offer us more time during which value may be realized. The framework I have described thus sees time as a boundary encompassing human agency as a whole. Each additional future human life merely expands the area inside that boundary. Scheffler's framework, in contrast, sees time as normatively structuring individual human lives, lives that overlap in time and thereby become normatively entangled, as past traditions shape current practices and current practices shape future hopes.

Note that I have not argued in favor of either Scheffler's evaluative framework or the alternative described here. In this respect, my conclusions are friendly to Scheffler, inasmuch as they indicate that the case for the afterlife conjecture need not rest on the four specific features he ascribes to our evaluative frameworks.

\section{References}

Behrendt, Kathy. 2007. Reasons to be fearful: Strawson, death and narrative. Royal Institute of Philosophy Supplement 60: 133-154.

LeGuin, Ursula K. 1973. The ones who walk away from Omelas, New Dimensions, vol. 3. New York: Doubleday.

Lenman, James. 2002. On becoming extinct. Pacific Philosophical Quarterly 83: 253-269.

MacIntyre, Alasdair. 1984. After virtue, 2nd ed. Notre Dame: University of Notre Dame Press. 
Nagel, Thomas. 1970. Death. Nous 4: 73-80.

Scheffler, Samuel. 2013. Death and the afterlife, ed. N. Kolodny. New York: Oxford University Press. Strawson, Galen. 2004. Against narrativity. Ratio 17: 428-452.

Strawson, Galen. 2007. Episodic ethics. Royal Institute of Philosophy Supplement 60: 85-116. Williamson, Timothy. 2006. Conceptual truth. Aristotelian Society Supplementary 80: 1-41. 